
Military Technical College
Kobry Elkobbah,
Cairo, Egypt

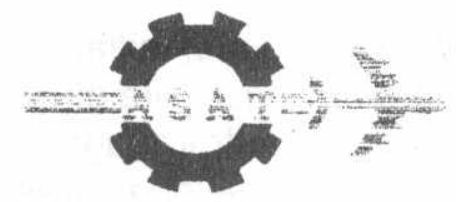

$8^{\text {th }}$ International Conference on Aerospace Sciences \&

Aviation Technology

\title{
Effect of Autofrettage on Fracture Toughness and Fatigue Crack Growth in Thick-Walled Tubes
}

\author{
Y. I. El-Shaer*, M. M. Mostafa** and M. S. Abdel-Kader**
}

\section{ABSTRACT}

The autofrettage process is normally used to produce favorable residual compressive stress field near the bore of a thick-walled tube, thus increasing its loading capacity and/or reducing its weight. This process retards the initiation and propagation of radial cracks in the bore [1]. On the other hand, the plastic deformation and hardening which occur in the cylinder due to autofrettage are likely to decrease the fracture toughness of the material, which, in turn, decreases the fatigue life.

In the present work, the effect of autofrettage on fracture toughness is first investigated using standard arc-shaped specimens cut from tubes with different overstrains. It is found that increasing autofrettage overstrain to about $100 \%$ reduces the fracture toughness of the material by about $20 \%$. Secondly, the effect of autofrettage on fatigue crack growth of internal cracks is studied experimentally using ring specimens. Furthermore, a mathematical model using the superposition principle is developed and used to predict fatigue crack growth for the specimens used. Comparison between experimental and predicted results is performed and good agreement is generally obtained.

It seems that there is an optimum value of autofrettage overstrain, which increases fatigue life and resistance to sudden failure. This value depends on the tube material and loading conditions. Further experimentation is yet to be done to confirm these results.

\section{KEY WORDS}

Autofrettage, Fracture toughness, Fatigue, Crack growth, Residual stresses, Thick-walled tubes.

\section{Introduction}

A thick-walled tube is a common configuration which is used in many industrial and military applications. To increase the pressure-bearing capacity of such tubes, beneficial residual compressive stresses are induced at the bore by the socalled autofrettage process.

* Assistant Lecturer, ** Assoc. Prof., Dept. Mech. Engineering, M.T.C., Cairo, Egypt. 
During the service life of thick-walled tubes, initiation of cracks in the inner surface occurs, which affects the overall service life of tubes diversely, specially due to dynamic loading. As the degree of autofrettage increases, retardation of crack growth occurs due to the compressive residual stresses on the crack face. On the other hand, the fracture toughness of the material decreases due to the plastic deformation, which occurs during the autofrettage process.

This work is directed to investigate, experimentally and theoretically, the effect of degree of autofrettage on fracture toughness and crack growth of thick-walled tubes. The experimental part includes the measurement of fracture toughness and fatigue crack growth in tubes with different degrees of autofrettage. The theoretical part aims at the development of a mathematical model to accurately predict crack growth through the tube walls. The model makes use of predicted residual stress distribution, the superposition principle, and use of Paris law. The optimum value of autofrettage, which gives the maximum fatigue life of the tube, will be sought as well.

\section{Experimental Work}

\subsection{Effect of Autofrettage on Fracture Toughness:}

As the fracture toughness depends on specimen dimensions, it was required to get specimen dimensions which validate the ASTM requirements for $K_{I C}$ testing. $A$ compact test specimen was first manufactured according to $\mathrm{K}_{\mathrm{IC}}$ values obtained from previous investigations on similar materials. The specimen dimensions are shown in Fig. 1. A fracture toughness test was performed on this specimen, and the calculated fracture toughness value indicates that the value of $2.5\left(\mathrm{~K}_{\mathrm{IC}} / \mathrm{Y}^{\prime}\right)^{2}$ is equal to $16.7 \mathrm{~mm}$. It was found, however, that the dimensions of the available stock of material could not provide a specimen with the required-size. The specimen thickness $(B)$, and crack-to-width ratio ( $\mathrm{a} / \mathrm{W})$ range could be achieved, while the requirement on $(\mathrm{W}-\mathrm{a})$ could not be achieved.

Due to the difficulties encountered in testing complete ring specimens (fixation problems and the problem of measuring crack opening displacement for such small rings), specimens used in the present work are arc-shaped specimens. These were cut from rings with different degrees of autofrettage. Of course, redistribution of the existing residual stresses in the rings takes place after being cut to arc-shaped specimens, but plastic deformation and strain hardening of the material (which affect fracture toughness [1]) still exist in the arc-shaped specimens.

The mechanical notch and the knife-edge, which is used for fixation of crack opening displacement (COD) gauge, were machined in the specimens using an EDM wire cutting machine. The notch and knife-edge shapes are shown in Fig. 2.

Arc-shaped specimens cut from as-received tubes with different a/ $\mathrm{W}$ ratio, were first tested to investigate the effect of short crack size on fracture toughness value. Then, Arc-shaped specimens cut from tubes with different degrees of autofrettage, with approximately the same a/W ratio, were tested to get the effect of autofrettage on fracture toughness. 


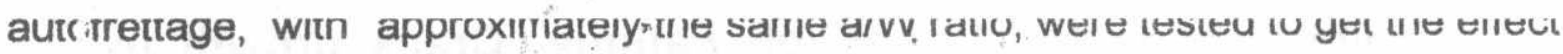
of a stofrettage on fracture toughness.

Tests were performed using MTS servo-hydraulic testing machine. The prer racking process was performed applying a load of $12 \mathrm{kN}$ (which corresponds to an approximate stress intensity factor of $50 \mathrm{MPa} \sqrt{m}$ ) at a frequency of $3 \mathrm{~Hz}$. When the fatigue crack occurs, an increasing load is applied to the specimen with a riate of $1.25 \mathrm{kN} / \mathrm{s}$ until fracture. The crack opening displacement was measured using a clip gauge type MTS 632 02C-20. The load versus COD curves was obtained using an xy-recorder type MTS 431.

The fracture toughness $K_{Q}$ for the arc-shaped specimen is given by [2]:

$$
\mathrm{K}_{\mathrm{Q}}=\left(\mathrm{P}_{\mathrm{Q}} / \mathrm{B} \sqrt{\mathrm{W}}\right)\left(\frac{3 \mathrm{X}}{\mathrm{W}}+1.9+1.1 \frac{\mathrm{a}}{\mathrm{W}}\right)\left(1+0.25\left(1-\frac{\mathrm{a}}{\mathrm{W}}\right)^{2}\left(1-\frac{\mathrm{r}_{1}}{\mathrm{r}_{2}}\right)\right) \mathrm{f}\left(\frac{\mathrm{a}}{\mathrm{W}}\right),
$$

where $P_{Q}$ is the load determined from load-COD curve, $B$ is the specimen thickness, $X$ is the loading hole offset, $a$ is the crack length (cf. Fig. 2) and $f(a / W$ ) is given by:

$$
f\left(-\frac{x}{W}\right)=\left(\frac{\sqrt{\frac{a}{W}}}{\left(1-\frac{a}{W}\right)^{3 / 2}}\right)\left(3.74-6.30 \frac{a}{W}+6.32\left(\frac{a}{W}\right)^{2}-2.43\left(\frac{a}{W}\right)^{3}\right) .
$$

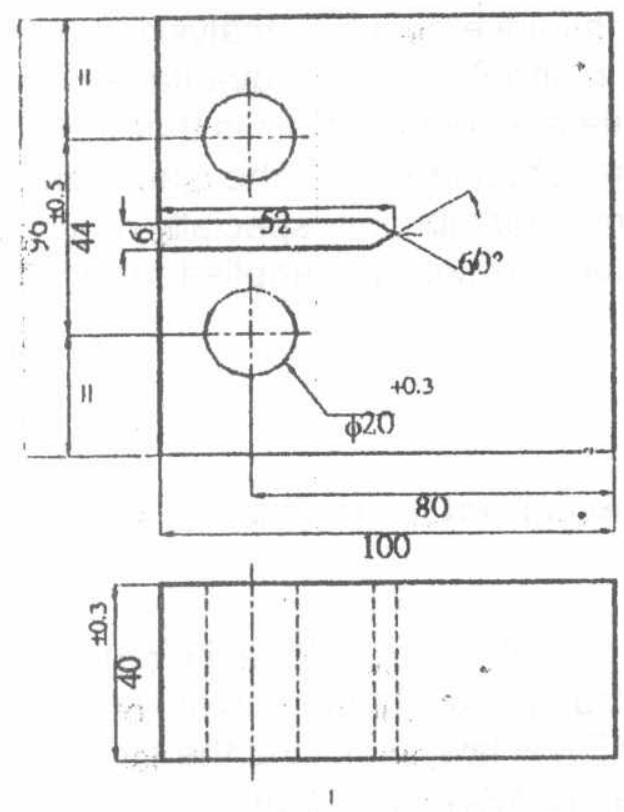

Fig. 1. Dimensions of compact test specimen.

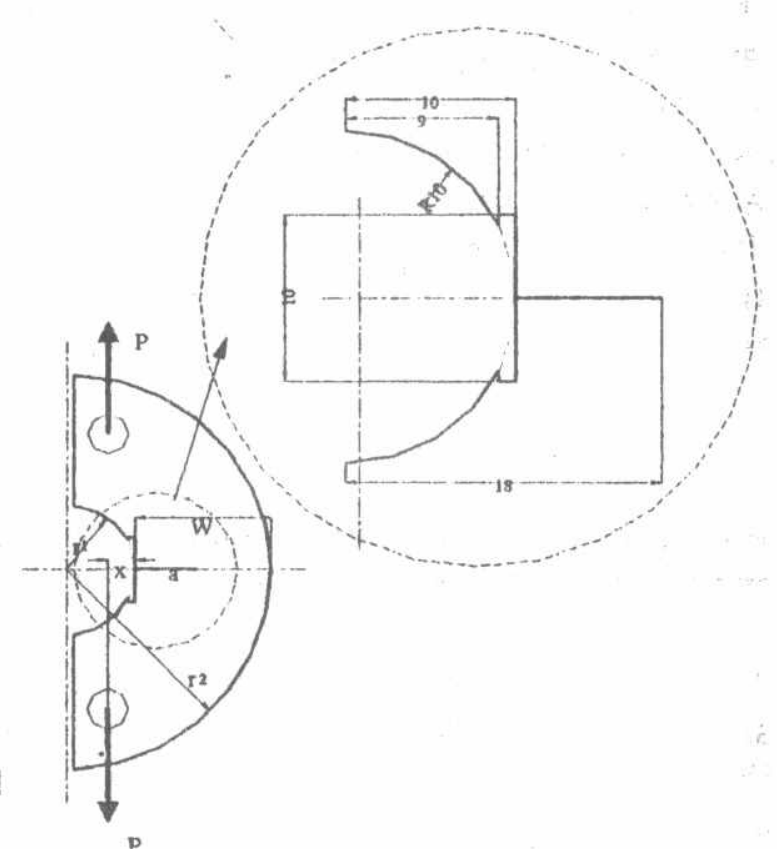

Fig.2. Notch and knife-edges in arcshaped specimen using EDM wire cutting machine. 


\subsection{Experimental Measurement of Fatigue Crack growth in Autofrettaged Thick-Walled Tubes}

To investigate crack growth in autofrettaged thick-walled tubes, ring specimens with uniform thickness of $5 \mathrm{~mm}$ were manufactured from as-received and autofrettaged thick-walled tubes. Specimens were notched in the internal surface using the EDM wire cutting machine, and subjected to a diametral tensile force to initiate an edge crack propagating in the radial direction. A problem of tearing of the specimens behind the hole used for fixation during loading took place. To overcome this problem a new shape of the ring specimen was proposed, in which the thickness of the specimen in the crack plane differs from that in the fixation position, as shown in Fig. 3.

Modified ring specimens with different degrees of autofrettage were tested at the stress ratio of 0.01 , which simulates repeated firing of a gun barrel. Different loads from $15 \mathrm{kN}$ to $25 \mathrm{kN}$ were applied to the specimens to get crack growth rates greater than $10^{-10} \mathrm{~m} /$ cycle [3].

To measure the crack size during fatigue, a scale with divisions of $0.5 \mathrm{~mm}$ was fixed on the specimen, parallel to the crack growth plane and a hand microscope was used to magnify the crack. To increase the visibility of the crack, the specimen side was coated by a thin film of brittle lacquer, which is cracked by the same value during crack growth.

\section{Mathematical Modeling of Fatigue Crack Growth}

The fatigue crack growth of thick-walled tubes was studied on tubes with a radius ratio of 3 . This problem can be investigated either by finite element analysis $[4,5$ and 6] or by using the superposition principle [7, 8 and 9]. The disadvantage of using the thermal simulation technique during finite element analysis is that this technique provides results that are close to those obtained using the classical Hill's model, which overestimates the residual stress distribution, specially near the bore. So, in the present work the principle of superposition was applied, using

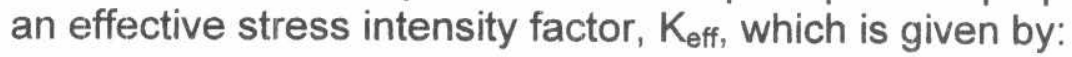

$\mathrm{K}_{\mathrm{eff}}=\mathrm{K}_{\mathrm{app}}+\mathrm{K}_{\mathrm{res}}$

where $K_{\text {app }}$ is the stress intensity factor caused by the applied force, and $K_{\text {res }}$ is the stress intensity factor caused by residual stresses.

A program was constructed using $\mathrm{C}++$ language to calculate the fatigue life of the specimen. The fatigue crack growth rate was calculated using the power law of Paris and Erdogan [10], which is widely known as Paris law, replacing the stress intensity range $\Delta \mathrm{K}$ by the effective stress intensity range $\Delta \mathrm{K}_{\text {eff }}$ as follows:

$\frac{\mathrm{da}}{\mathrm{dN}}=\mathrm{C} . \Delta \mathrm{K}_{\mathrm{eff}}^{\mathrm{m}}$,

where $\mathrm{C}$ and $\mathrm{m}$ are material constants that are determined experimentally. A block diagram of the calculation procedure in this program is shown in Fig. 4. 


\subsection{Determination of stress intensity factor for thick- walled ring specimen}

To determine the stress intensity factor for a thick-walled ring subjected to diametric load using the compliance method, a model of the specimen was made and analyzed using COSMOS finite element analysis program. A program was made to change the crack size and calculate the corresponding displacement. The compliance was then calculated and used to calculate the stress intensity factor. Further details can be found in Ref. [11].

The normalized stress intensity factor defined as:

$$
\mathbf{K}_{\mathrm{LN}}=\frac{\mathbf{K}_{\mathrm{I}} \mathbf{W B}}{\mathbf{P} \sqrt{\pi \mathrm{a}}},
$$

was plotted as function of a/W in Fig. 5 and fitted by the polynomial:

$$
\begin{aligned}
K_{I N}= & 2.26732-5.07332 \frac{a}{W}-8.15838\left(\frac{a}{W}\right)^{2}+105.85188\left(\frac{a}{W}\right)^{3}-332.20218\left(\frac{a}{W}\right)^{4} \\
& +509.66647\left(\frac{a}{W}\right)^{5}-391.07284\left(\frac{a}{W}\right)^{6}+120.20211\left(\frac{a}{W}\right)^{7}, \\
& (0.05 \leq \mathrm{a} / \mathrm{W} \leq 0.9) .
\end{aligned}
$$

A comparison between values of $K_{1}$ calculated from the computer program and those obtained from Eqn. $\left(K_{\mathrm{I}}=\frac{\mathrm{P}}{\mathrm{W} \cdot \mathrm{B}} \sqrt{\pi \mathrm{a}} \mathrm{K}_{\mathrm{IN}}\right)$ was made and a very good accuracy was obtained, as may be seen from Fig. 6.
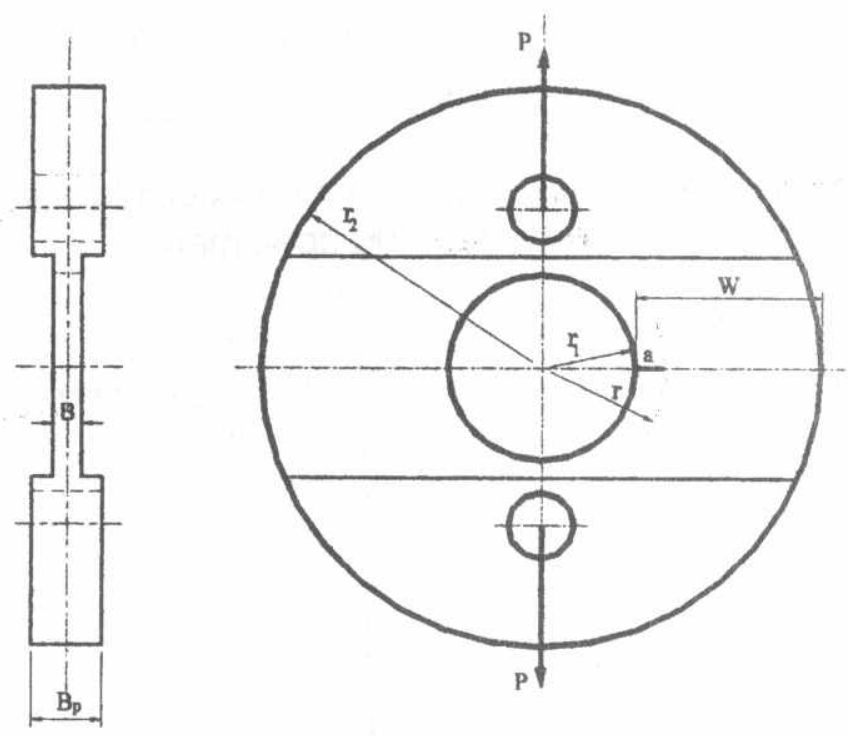

Fig.3. Modified ring specimen. 


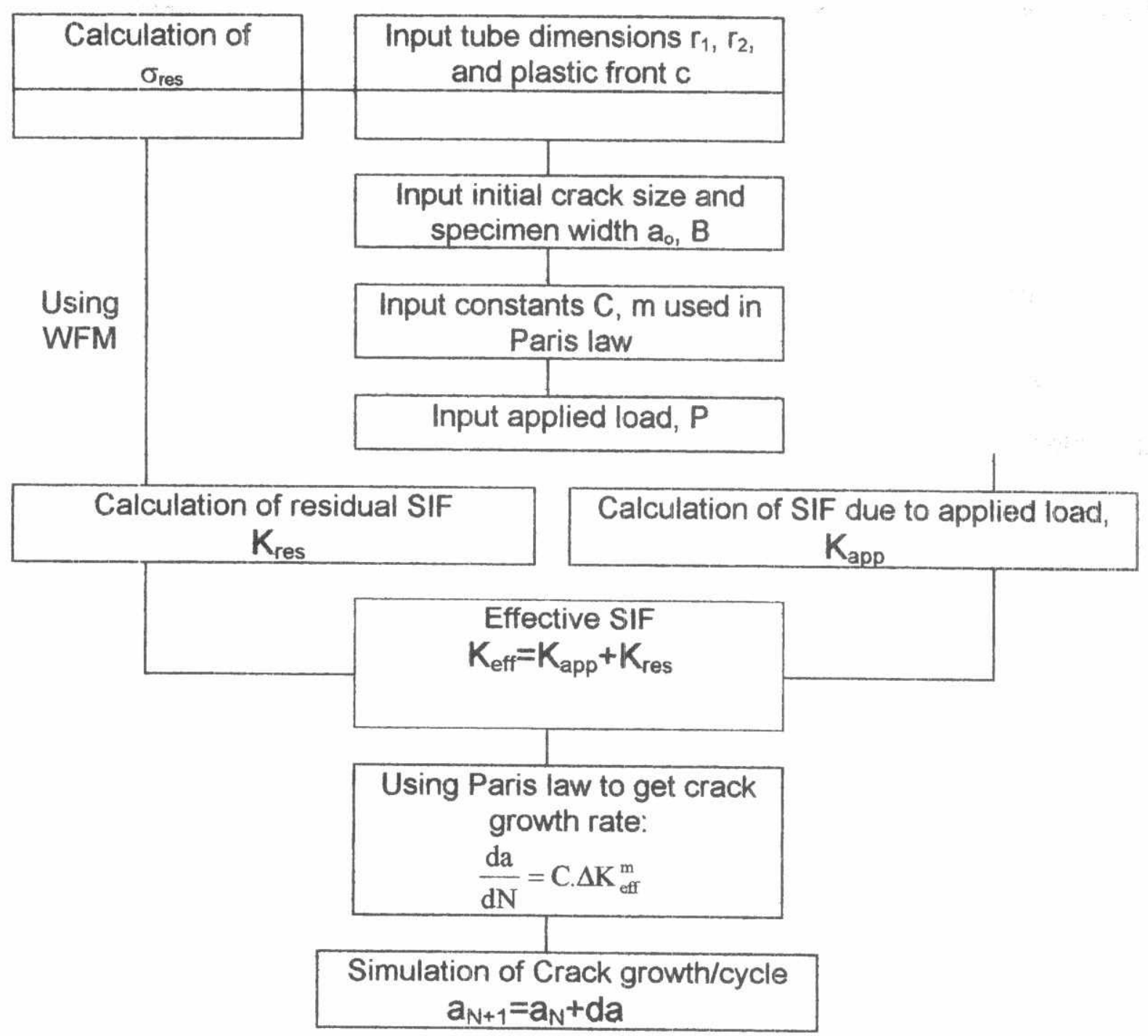

Fig.4. Calculation procedure in the program used to calculate fatigue crack growth of autofrettaged ring specimens.

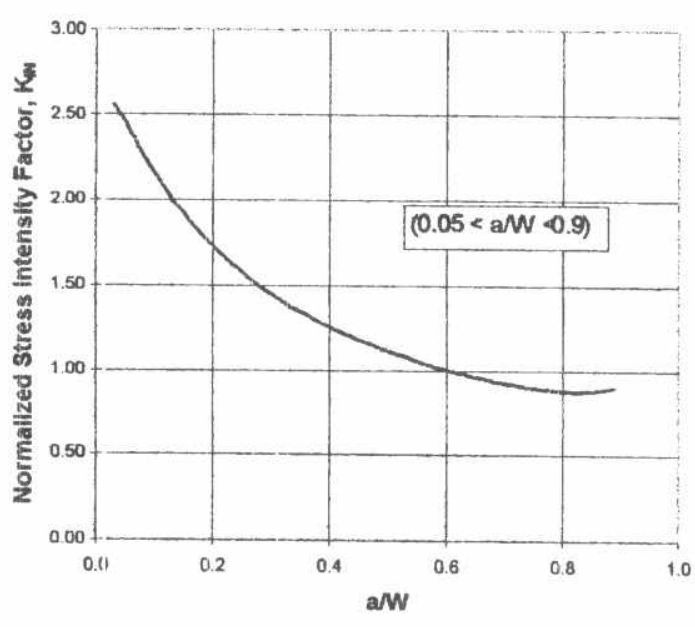

Fig.5. Normalized stress intensity factor versus $\mathrm{a} / \mathrm{W}$.

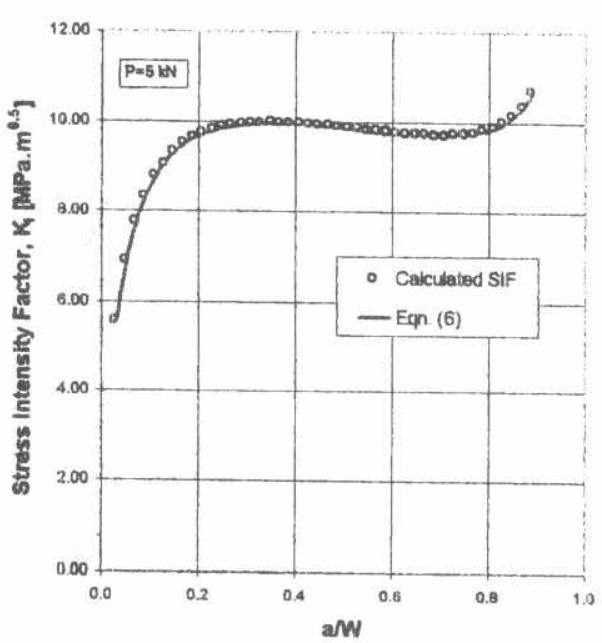

Fig.6. Fitting of stress intensity factor as function of $a / W$ to Eqn. (6). 


\subsection{Calculation of residual stress intensity factor}

In order to calculate the residual stress intensity factor, the weight function method is used [3]. The weight function method is an analytical technique for deriving stress intensity factors from knowledge of the stress distribution in the uncracked body. It has been shown that knowledge of stress intensity factor and displacement field for a flawed geometry enables construction of a weight function, which depends only on the geometry [12]. Using this function, additional stress intensity factor solutions may be obtained for any other stress distribution, such as the residual stress distribution, res $(x)$, so that:

$$
\mathrm{K}_{r e s}=\int \sigma_{r e s}(x) \cdot W(x, a) \cdot d x .
$$

There are several techniques used to get the weight function for a cracked geometry. The method used by Stacey and Webster [14] is chosen and used here due to its relative simplicity. The weight function is assumed to have the form:

$$
W(x, a)=2 \frac{\sqrt{\frac{a}{\pi}}}{\sqrt{a^{2}-x^{2}}} \cdot\left[m_{0}-\left(m_{0}-1\right) \frac{x}{a}\right],
$$

where $m_{0}$ is equivalent to $m(0, a)$. For a cracked body subjected to a stress field $\sigma(\mathbf{x})$ :

$\mathrm{K}=\int_{0}^{\mathrm{a}} \sigma(\mathrm{x}) \cdot 2 \frac{\sqrt{\frac{\mathrm{a}}{\pi}}}{\sqrt{\mathrm{a}^{2}-\mathrm{x}^{2}}} \cdot\left[\mathrm{m}_{0}-\left(\mathrm{m}_{\mathrm{o}}-1\right) \frac{\mathrm{x}}{\mathrm{a}}\right] \cdot \mathrm{dx}$.

Equation 10 is used to get $m_{0}$ for a given value of a using the $K$ solution corresponding to the stress distribution $(x)$. $K_{\text {res }}$ is then calculated from Eqn. 8. The calculated $m_{0}$ is shown in Fig. 7 as a function of $a / W$. Further details can be found in Ref. [11]. The calculated value of $m_{0}$ was fitted as a function of a/W by the polynomial:

$$
\begin{aligned}
\mathrm{m}_{\mathrm{o}}= & 0.93005+4.54744 \frac{\mathrm{a}}{\mathrm{w}}-58.63949\left(\frac{\mathrm{a}}{\mathrm{w}}\right)^{2}+329.08173\left(\frac{\mathrm{a}}{\mathrm{W}}\right)^{3}-942.59321\left(\frac{\mathrm{a}}{\mathrm{W}}\right)^{4} \\
& +1463.366181\left(\frac{\mathrm{a}}{\mathrm{W}}\right)^{5}-1162.27409\left(\frac{\mathrm{a}}{\mathrm{w}}\right)^{6}+371.08004\left(\frac{\mathrm{a}}{\mathrm{w}}\right)^{7}
\end{aligned}
$$

To check the calculated weight function, the crack face displacement was calculated using both weight function method and finite element method and compared in Fig. 8 and good agreement was generally obtained.

The residual stress intensity factor, $\mathrm{K}_{\text {res, }}$ calculated using the weight function method is shown in Fig. 9 and is similar to that obtained by Stacey and Webster $[9,13]$. As may be seen from the figure, the residual stress intensity factor 
increases with increasing the crack size until a maximum value is reached, which depends on the degree of autofrettage, and then decreases again.

As the degree of autofrettage increases, the residual stress intensity factor increases, but the relative increase in residual stress intensity factor tencls to decrease at higher degrees of autofrettage. This may be attributed to the reduction in the beneficial residual hoop stress, which occurs with increasing autofrettage degree due to the reverse plasticity effect.

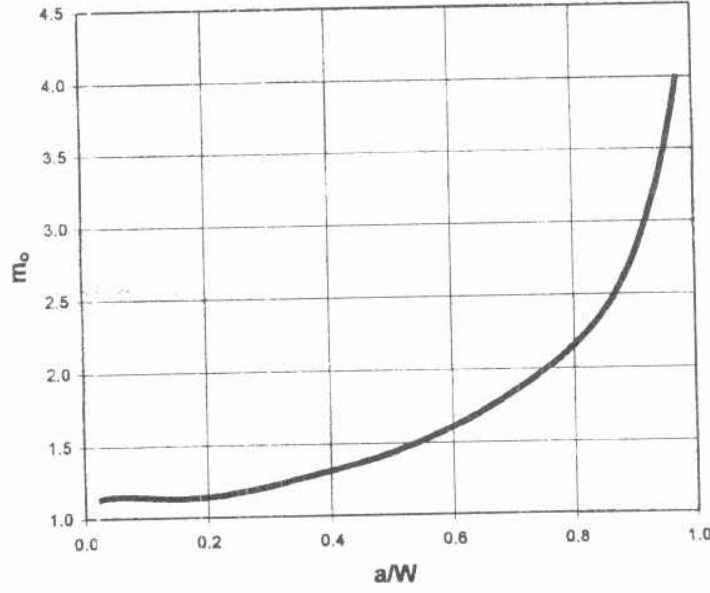

Eig.7. Variation of $m_{0}$ with a $/ W$.

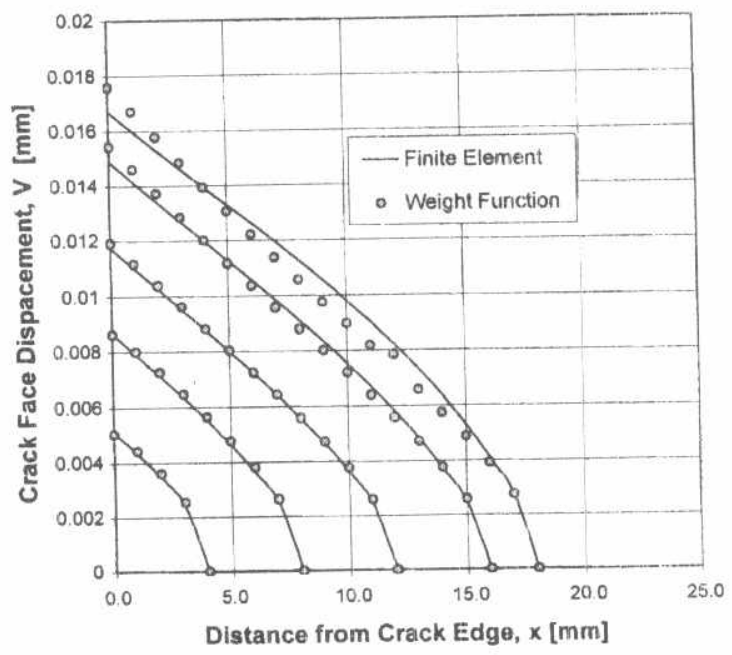

Fig.8. Crack face displacement using weight function method and finite element method for ring specimen.

\section{Results and Discussion:}

\subsection{Effect of autofrettage on fracture toughness}

The results of fracture toughness tests performed on as-received and autofrettaged arc-shaped specimens are listed in Table 1. The effect of autofrettage on fracture toughness is shown in Fig.10. It is clear that with increasing the degree of autofrettage, fracture toughness is reduced. The relative reduction in fracture toughness between the as-received specimen and the $100 \%$ autofrettaged specimen is about $20 \%$.

In their experiments performed on ring specimens, Banks-Sills and Marmour [1] found that the reduction in fracture toughness amounts to $60 \%$, which is much larger than the value reported here for the arc-shaped specimen. This difference may be attributed to the relaxation of considerable part of the residual stresses during manufacturing of the arc-shaped specimens from the autofrettaged rings. To get more accurate results, experiments should be done on standard specimens which satisfy the conditions of plane-strain fracture toughness testing. Unfortunately, such specimens were not available, essentially due to the linited dimensions of the available stock of material used in the present work. 


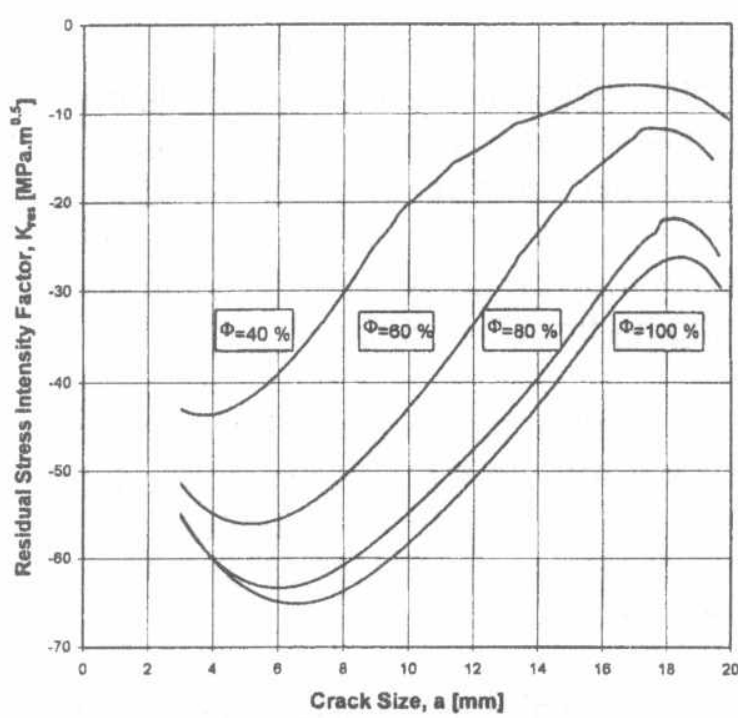

Fig.9. Residual stress intensity factor for ring specimens with different overstrains using weight function method.

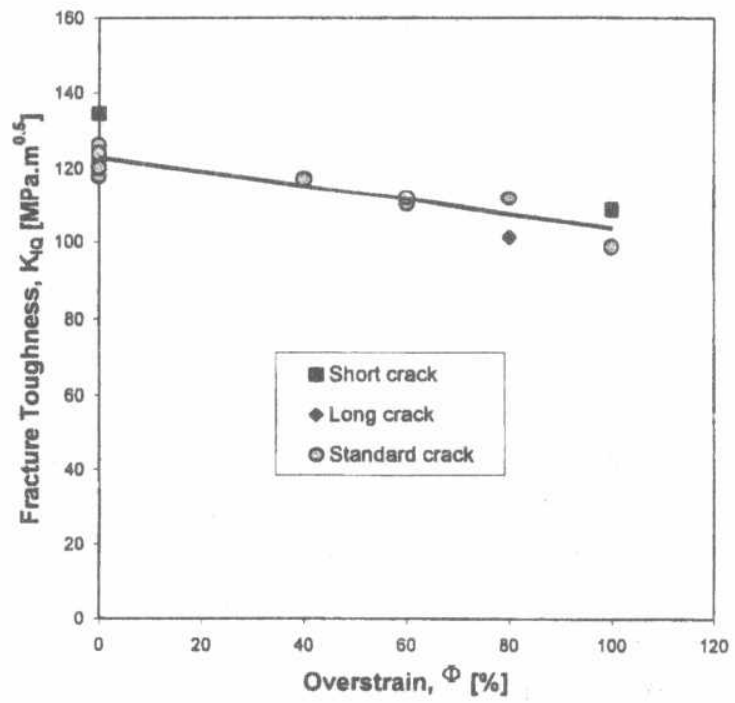

Fig.10. Effect of autofrettage overstrain on fracture toughness.

Table 1. Fracture toughness test results of arc-shaped specimens

\begin{tabular}{|c|c|c|c|c|c|c|c|c|c|}
\hline $\begin{array}{l}\text { Spec. } \\
\text { No. }\end{array}$ & $\begin{array}{c}\Phi \\
{[\%]}\end{array}$ & $\begin{array}{c}\mathrm{W} \\
{[\mathrm{mm}]}\end{array}$ & $\begin{array}{c}B \\
{[\mathrm{~mm}]}\end{array}$ & $\begin{array}{c}x \\
{[\mathrm{~mm}]}\end{array}$ & $\begin{array}{c}a \\
{[\mathrm{~mm}]}\end{array}$ & $a / W$ & $\begin{array}{c}\mathrm{Pa} \\
{[\mathrm{KN}]}\end{array}$ & $\begin{array}{l}P_{\max } \\
\text { [KN] }\end{array}$ & $\begin{array}{c}K_{\mathrm{IQ}} \\
{\left[\mathrm{MPa} \cdot \mathrm{m}^{0.5} \text { ] }\right.}\end{array}$ \\
\hline $1 / 0$ & 0 & 19,5 & 20.4 & 3.8 & 5.65 & .29 & 58.7 & 65.3 & 134.59 \\
\hline $2 / 0$ & 0 & 19.8 & 20.4 & 3.8 & 6.00 & .303 & 53.6 & 59.4 & 126.16 \\
\hline $3 / 0$ & 0 & 20.0 & 20.0 & 3.8 & 9.23 & .462 & 33.3 & 37.4 & 122.66 \\
\hline $4 / 0$ & 0 & 20.0 & 20.0 & 3.8 & 8.60 & .43 & 35.1 & 40.5 & 117.57 \\
\hline $5 / 0$ & 0 & 20.0 & 20.0 & 3.8 & 7.75 & .388 & 40.4 & 45.8 & 120.23 \\
\hline $6 / 0$ & 0 & 20.0 & 20.0 & 3.8 & 8.325 & .416 & 38.1 & 40.9 & 124.13 \\
\hline $1 / 40$ & 40 & 19.6 & 20.0 & 3.8 & 8.70 & .445 & 33.0 & 35.1 & 117.33 \\
\hline $2 / 40$ & 40 & 19.6 & 20.0 & 3.8 & 9.00 & .462 & 31.3 & 33.7 & 116.92 \\
\hline $1 / 60$ & 60 & 19.6 & 20.0 & 3.8 & 10.6 & .523 & 24.2 & 26.5 & 109.95 \\
\hline $2 / 60$ & 60 & 19.6 & 20.0 & 3.8 & 10.22 & .487 & 27.7 & 30.8 & 111.85 \\
\hline $1 / 80$ & 80 & 19.7 & 20.0 & 3.8 & 12.4 & .626 & 15.2 & 17.4 & 101.2 \\
\hline $2 / 80$ & 80 & 19.7 & 20.0 & 3.8 & 10.6 & .541 & 23.1 & 26.2 & 111.51 \\
\hline $1 / 100$ & 100 & 19.6 & 20.0 & 3.8 & 5.8 & .297 & 45.8 & 52.5 & 108.41 \\
\hline $2 / 100$ & 100 & 19.6 & 20.0 & 3.8 & 9.8 & .5 & 23.5 & 26.9 & 98.85 \\
\hline
\end{tabular}




\subsection{Effect of Autofrettage on Fatigue Crack Growth}

Fatigue crack growth experiments were confined to ring specimens only. The dimensions of the tested ring specimens with different overstrains are listed in Table 2, together with pertinent loading parameters. The crack growth curves were compared with those obtained using the theoretical model described in Sec. 3. Sample results are shown in Figs. 11 to 14 . For the $40 \%$ overstrain specimens (Fig. 11), the experimental and model results may be considered to be in good agreement, except probably for crack sizes ranging from 3 to $5 \mathrm{~mm}$.

For the $60 \%$ overstrain specimens, good agreement between the experimental and model results are obtained for small crack sizes. As the crack size becomes larger than about $11 \mathrm{~mm}$, the difference increases. Similar responses can be observed in Figs. 13 and 14 for rings with overstrain ratios of 80 and $100 \%$, respectively. Of course, quantitative differences do exist.

Parker, et al. [5] predicted lifetimes of autofrettaged thick-walled tubes on the basis of ideal residual stress field for semicircular cracks. They found that an increase of overstrain from 30 to $50 \%$ increases the predicted life by a factor of five, while the measured life was increased by a factor of 1.6 only. This difference between predicted and measured values was attributed to Baushinger effect and reverse yielding, which were not taken into account in their work.

Another aspect which was observed during testing of the ring specimens is that there was a strong tendency for initiation and propagation of a second fatigue crack in the side opposite to the initial crack (cf. Fig.15) although there was no mechanical notch in that side. This was observed in six specimens during testing. It is essential, therefore, that crack growth in ring specimens with two opposing cracks be investigated.

Table 2. Dimensions and loading parameters of fatigue crack growth specimens

\begin{tabular}{|c|c|c|c|c|c|c|c|c|c|c|}
\hline $\begin{array}{c}\text { Spec. } \\
\text { No. }\end{array}$ & $\begin{array}{c}\Phi \\
{[\%]}\end{array}$ & $\begin{array}{c}r_{1} \\
{[\mathrm{~mm}]}\end{array}$ & $\begin{array}{c}\mathbf{r}_{2} \\
{[\mathrm{~mm}]}\end{array}$ & $\begin{array}{c}\text { B } \\
{[\mathrm{mm}]}\end{array}$ & $\begin{array}{c}\mathbf{B}_{\mathrm{p}} \\
{[\mathrm{mm}]}\end{array}$ & $\begin{array}{l}P_{\max } \\
{[\mathrm{kN}]}\end{array}$ & $\begin{array}{l}P_{\text {min }} \\
{[\mathrm{kN}]}\end{array}$ & $\begin{array}{c}\mathrm{fr} \\
{[\mathrm{Hz}]}\end{array}$ & $\begin{array}{c}a_{0} \\
{[\mathrm{~mm}]}\end{array}$ & $\begin{array}{c}a_{f} \\
\operatorname{limm}]\end{array}$ \\
\hline $1 / 0$ & 0 & 10 & 30 & 2 & 5 & 14.77 & 0.19 & 1 & 4.25 & 19 \\
\hline $1 / 40$ & 40 & & & & & 19.88 & 2.84 & 3 & 3.00 & 16 \\
\hline $1 / 60$ & 60 & & & & & 22.35 & 0.95 & 2 & 3.25 & 16.5 \\
\hline $1 / 80$ & 80 & & & & & 24.62 & 0.38 & 1 & 5.75 & 15 \\
\hline $1 / 100$ & 100 & & & & & 22.35 & 0.95 & 2 & 3.25 & 15 \\
\hline
\end{tabular}




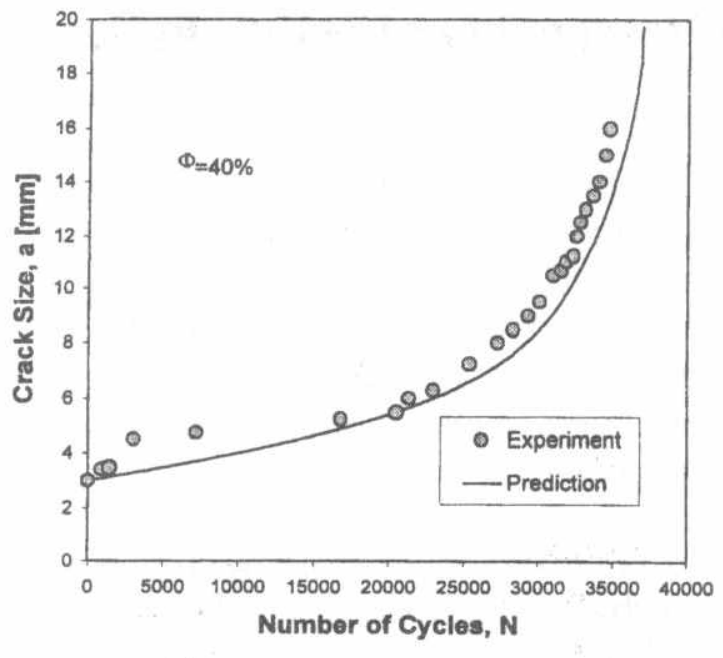

Fig.11. Predicted versus measured crack growth response, $\Phi=40 \%$.

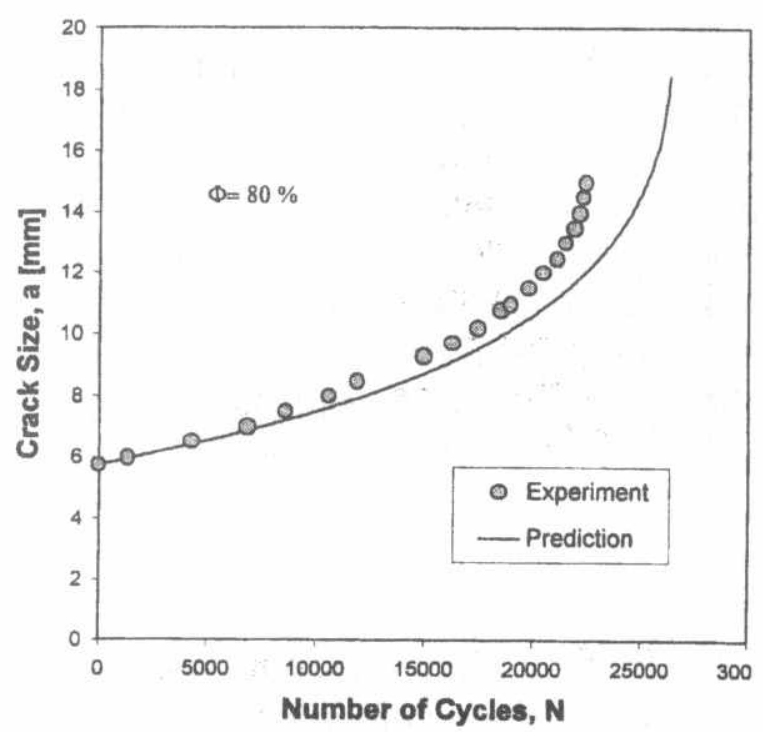

Fig. 13. Predicted versus measured crack growth response, $\Phi=80 \%$.

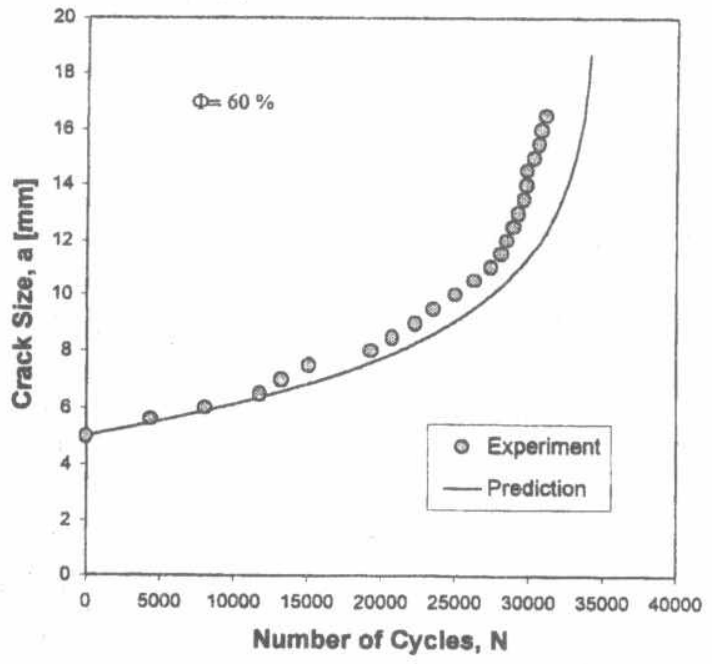

Fig.12. Predicted versus measured crack growth response, $\Phi=60 \%$.

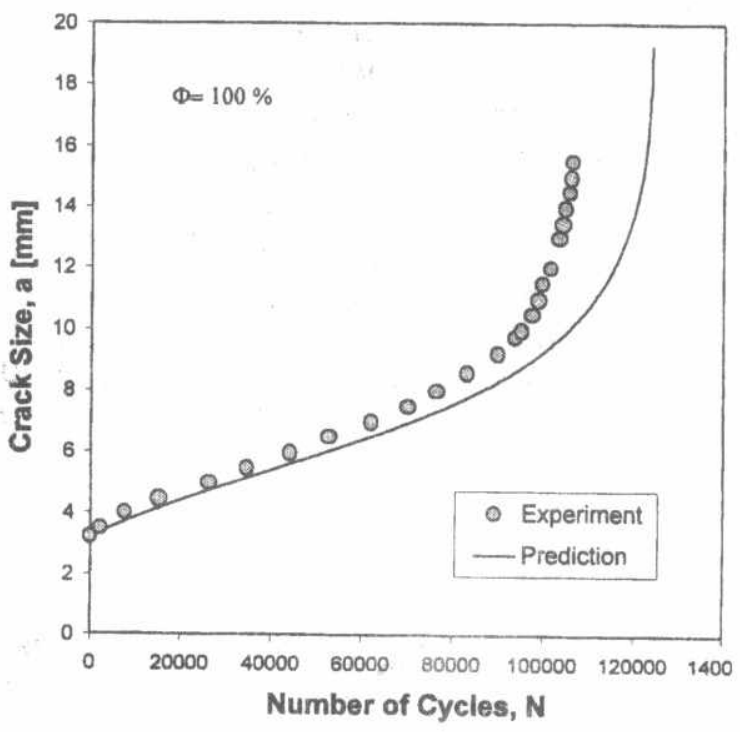

Fig.14. Predicted versus measured crack growth response, $\Phi=100 \%$.

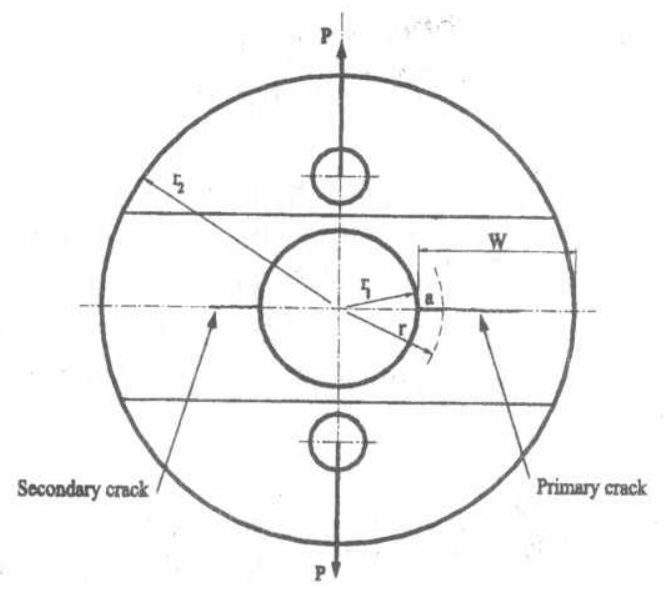

Fig.15. Secondary crack initiation in ring specimen. 


\subsection{Effect of loading conditions on fatigue life of autofrettaged rings}

In the present section the mathematical model is used to predict the fatigue crack growth and fatigue life of rings with different degrees of autofrettage and at different loading conditions. In the model, it is assumed that failure of rings occurs when the effective stress intensity factor reaches its critical value obtained from the experimental results. Three loads with values of $20,22.5$ and $25 \mathrm{kN}$, and 7 overstrain values ranging from 0 to $100 \%$ were used to investigate the effect of loading parameters on fatigue life of autofrettaged rings.

The crack growth curves obtained using the mathematical model are shown in Figs. 16 to 18. It can be seen from these figures that as the overstrain increases, the crack growth rate decreases and the total expected life increases for overstrains ranging from 0 to $80 \%$. For the higher overstrain values, the crack growth curves are seen to be very close to each other for $P=20 \mathrm{kN}$, Fig. 16, and become almost identical as $P$ increases, Figs. 17 and 18.

The fatigue lives for rings with different overstrains and at different loads were calculated and are shown in Figs. 19 to 21 . At $P=20 \mathrm{kN}$, Fig. 19, the beneficial effect of autofrettage can be observed clearly, with the optimum value of overstrain being lower than $100 \%$. As the applied load increases, (cf. Figs. 20 and 21) the optimum value of autofrettage, which gives maximum life, tends to decrease, as shown in Fig. 22 for a larger load span. This may be attributed to the decrease of the compressive residual stresses at the bore due to reverse plasticity effect. Furthermore, reduction of fracture toughness is another possible reason for this response, since it decreases the critical crack size and hence fatigue life.

\section{Conclusions}

Based on the results obtained from studying the effect of autofrettage on fracture toughness and fatigue crack growth, the following conclusions can be drawn:

a) Autofrettage decreases the fracture toughness of thick-walled tubes, and hence, decreases the critical crack size at which failure occurs. A maximum reduction of $20 \%$ in fracture toughness was observed when testing autofrettaged arc-shaped specimens cut from tubes with different overstrains.

b) A new ring specimen was proposed for fatigue crack growth experiments. The new specimen is capable of overcoming the difficulties encountered when experimenting with the standard specimen. The stress intensity factor and weight function were calculated for this specimen. The experimental crack growth results obtained using this specimen were in good agreement with the predicted results provided by Paris law.

c) Autofrettage increases the cycles required for fatigue crack initiation. As the overstrain increases, the number of cycles to crack initiation increases, 
until a limiting value is reached, after which the number of cycles decreases again.

d) Autofrettage process decreases fatigue crack growth rate, and hence, increases fatigue life. On the other hand, the critical crack size decreases as affected by the reduction of fracture toughness. So, an optimum overstrain value should be sought when designing and manufacturing autofrettaged thickwalled tubes. This optimum value depends on the material used and on the loading conditions.

\section{REFRENCES}

1. L. Banks-Sills and I. Marmour, "Influence of Autofrettage on Fracture Toughness", Journal of Fracture, Vol.40, pp. 143-155, (1988).

2. "Standard Test Method for Plane-Strain Fracture Toughness of Metallic Materials E399", Annual Book of ASTM Standards, Vol. 03.01, American Society for Testing and Materials, Philadelphia, pp. 506-526, (1990).

3. T. L. Anderson, "Fracture Mechanics Fundamentals and Applications", Ed. CRC Press, Inc., Florida, (1991).

4. S. Pu and M. Hussain, "Stress Intensity Factors for Radial Cracks in a Partially Autofrettageed Thick-Wall Cylinder", Fracture Mechanics: Fourteenth Symposium-Volume I: Theory and Analysis, ASTM STP 791, American Society for Testing and Materials, Philadelphia, pp. I-194-I-215, (1983).

5. H. Shu, J. Petit and G. Bezine, "Stress Intensity Factors for Radial Cracks in Thick Walled Cylinders-I. Symmetrical Cracks", Engineering Fracture Mechanics, Vol. 49, No. 4, pp. 611-623, (1994).

6. H. Shu, J. Petit and G. Bezine, "Stress Intensity Factors for Radial Cracks in Thick Walled Cylinders-II. Combination of Autofrettage and Internal Pressure ", Engineering Fracture Mechanics, Vol. 49, No. 4, pp. 625-629, (1994).

7. Parker, "Stress Intensity Factors, Crack Profiles, and Fatigue Crack Growth Rates in Residual Stress Fields", Residual Stress Effects in Fatigue, ASTM STP 776, American Society for Testing and Materials, pp. 13-31, (1982).

8. S. Pu. and P. Chen, "On Fatigue Life Calculation in Thick-Walled Cylinders with Complex Residual Stresses", Analytical and Experimental Methods for Residual Stress Effects in Fatigue, ASTM STP 1004, American Society for Testing and Materials, Philadelphia, pp. 54-64, (1988).

9. Stacey and G. Webster, "Influnce of Residual Stress on Fatigue Crack Growth in Thick-Walled Cylinders.", Analytical and Experimental Methods for Residual Stress Effects in Fatigue, ASTM STP 1004, American Society for Testing and Materials, Philadelphia, pp. 107-121, (1988).

10. P. C. Paris, F. Erdogan, "A Critical Analysis of Crack Propagation Laws.", Journal of Basic Engineering, Vol. 85, pp. 528-534, (1960).

11. Y. I. El-Shaer, "Effect of Residual Stresses on Fracture Toughness and Crack Growth in Thick-Walled Tubes", M. Sc. Thesis, Military Technical College, Cairo, Egypt, (1998).

12. S. Pu and P. Chen, "Stress Intensity Factors for Radial Cracks in a PreStressed, Thick-Walled Cylinder of Strain-Hardening Materials", Journal of Pressure Vessel Technology, Vol. 105, pp. 117-123, (1983). 
13. Stacey and G. Webster, "Stress Intensity Factors Caused by Residual Stress Fields in Autofrettaged Tubing.", Analytical and Experimental Methods for Residual Stress Effects in Fatigue, ASTM STP 1004, American Society for Testing and Materials, Philadelphia, pp. 37-53, (1988).

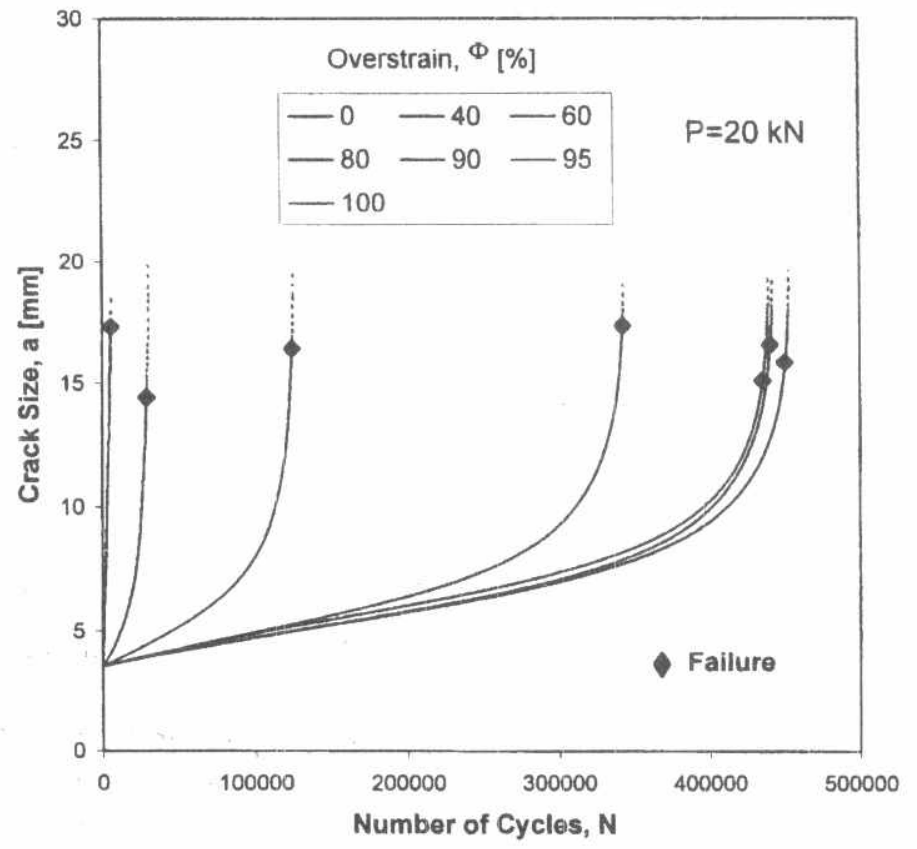

Fig.16. Predicted fatigue crack growth response for different overstrains, $P=20 \mathrm{kN}$.

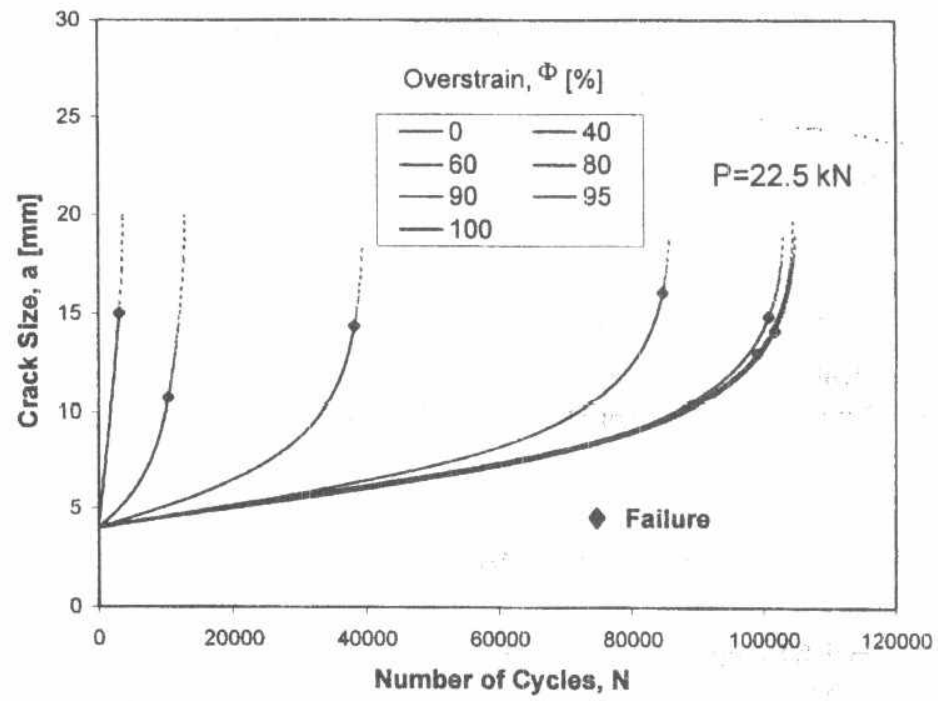

Fig.17. Predicted fatigue crack growth response for different overstrains, $P=22.5$ $\mathrm{kN}$. 


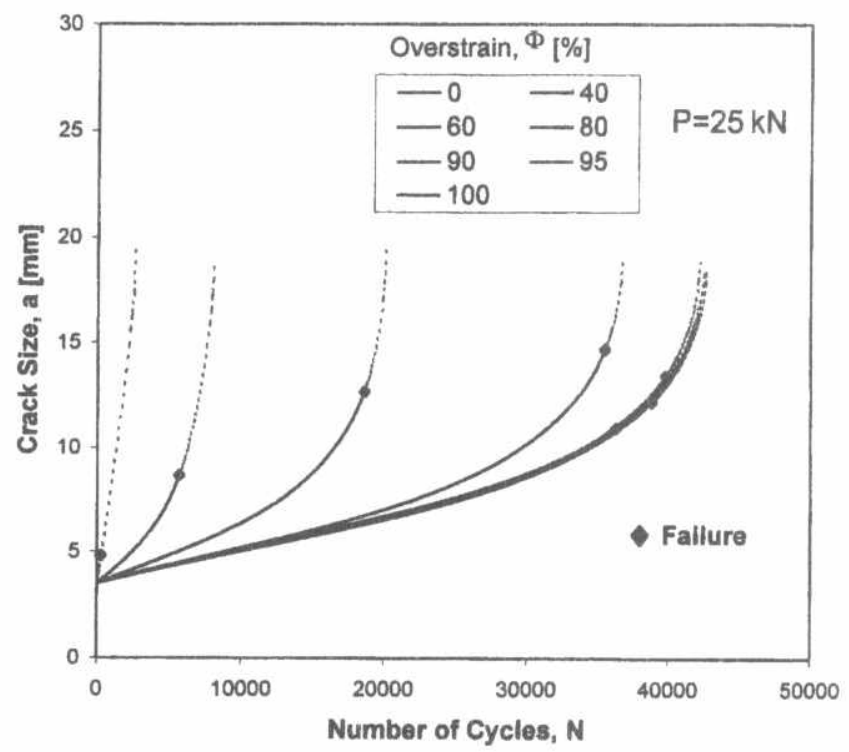

Fig. 18. Predicted fatigue crack growth response for different overstrains, $P=25 \mathrm{kN}$.

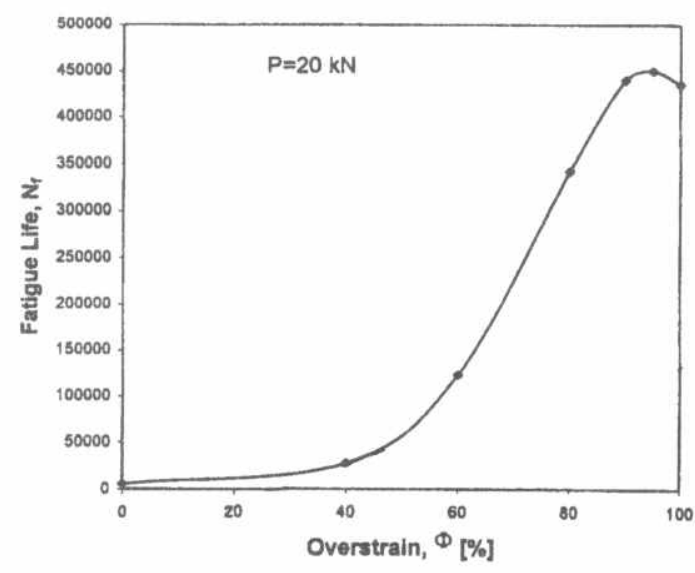

Fig.19. Predicted fatigue life versus overstrain, $\mathrm{P}=20 \mathrm{kN}$.

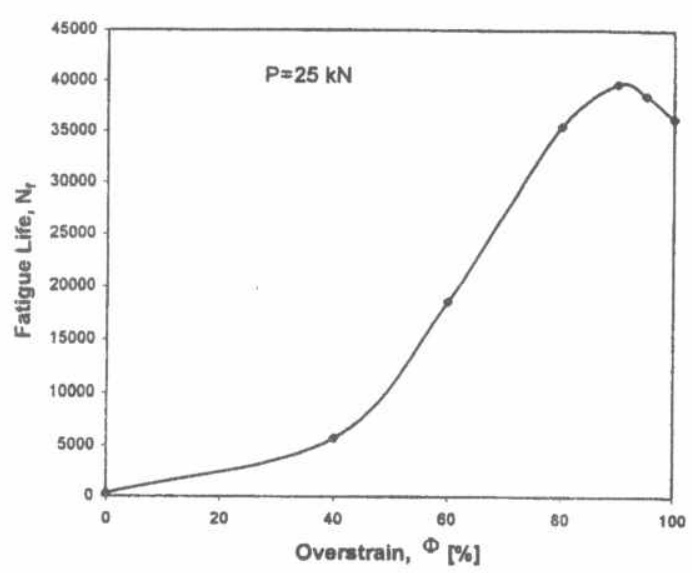

Fig.21. Predicted fatigue life versus overstrain, $\mathrm{P}=25 \mathrm{kN}$.

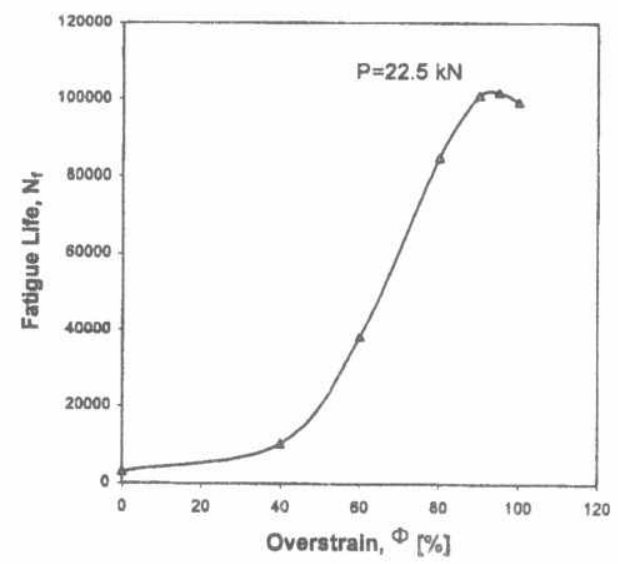

Fig.20. Predicted fatigue life versus overstrain, $\mathrm{P}=22.5 \mathrm{kN}$.

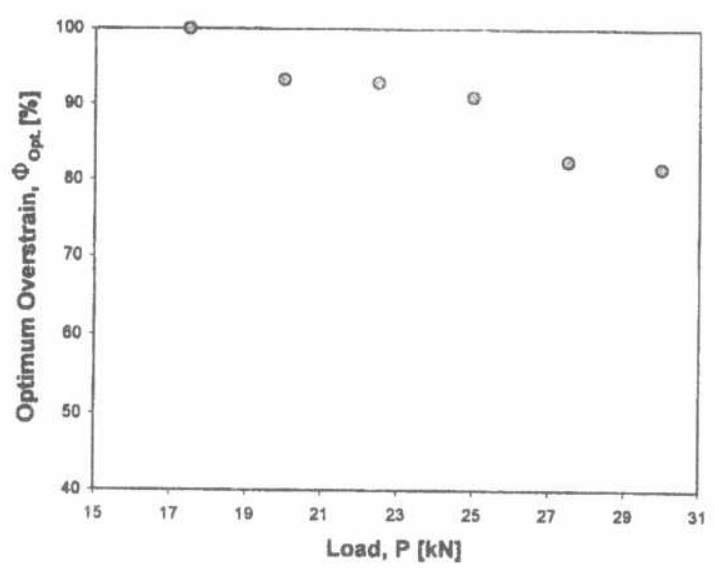

Fig.22. Effect of applied load on the optimum overstrain. 